\title{
Effects of moderate hyperhomocysteinaemia induced by 4 weeks methionine- enriched diet on metabolite profile and mesenteric artery function in rats
}

\author{
Annette Pexa ${ }^{1,2}$, Rainer H. Boeger ${ }^{3}$, Thomas Henle ${ }^{2}$, Edzard Schwedhelm ${ }^{3}$ and Andreas Deussen ${ }^{1 *}$ \\ ${ }^{1}$ Institute of Physiology, Medical Faculty Carl Gustav Carus, TU Dresden, Fetscherstr. 74, 01307 Dresden, Germany \\ ${ }^{2}$ Institute of Food Chemistry, TU Dresden, Bergstr. 66, 01062 Dresden, Germany \\ ${ }^{3}$ Institute of Experimental and Clinical Pharmacology and Toxicology, University Hospital Hamburg-Eppendorf, Martinistr. 52, \\ 20246 Hamburg, Germany
}

(Received 28 March 2007 - Revised 28 August 2007 - Accepted 20 September 2007 - First published online 25 February 2008)

Methionine is an essential amino acid and methyl donor for most transmethylation reactions in mammals. The product of transmethylation reactions is homocysteine, which is associated with enhanced risk for CVD. The aim of this study was to analyse metabolic and vascular functional consequences of a methionine-enriched diet in rats. The dose of methionine was chosen to reflect the range of over-nutrition in man. We quantified plasma levels of homocysteine, asymmetrical dimethylarginine and adenosine, determined methionine and its metabolites in tissues and blood plasma and assessed relaxation of mesenteric arteries toward acetylcholine and sodium nitroprusside. A methionine-enriched diet for 4 weeks elevated homocysteine levels in plasma 2-fold and in spleen by $70 \%$. The level of $S$-adenosylhomocysteine was increased in liver only, while methionine and $S$-adenosylmethionine were unchanged in all organs studied. Plasma adenosine and asymmetrical dimethylarginine levels were unchanged, as were vessel relaxations. A 2-fold elevation of plasma homocysteine, which is assigned a risk indicator for cardiovascular events, did not impair mesenteric artery vasodilatation during 4 weeks of a methionine-rich diet. Furthermore, asymmetrical dimethylarginine and adenosine, which have been shown to be changed in more severe degrees of hyperhomocysteinaemia, remained unaltered.

Homocysteine: Asymmetrical dimethylarginine: Amino acids: Vessel function

Methionine is an essential amino acid with a recommended daily intake of $1-2 \mathrm{~g}$ per $\mathrm{d}$ for human individuals ${ }^{(1)}$. Most methylation reactions in the body, e.g. methylation of RNA and DNA or synthesis of creatine or adrenaline, rely on methionine metabolism $^{(2)}$. In the respective pathway, methionine is coupled to ATP leading to formation of $S$-adenosylmethionine (SAM), which is the main methyl donor in mammals ${ }^{(3)}$. A product of the methyl transfer reactions is $S$-adenosylhomocysteine (SAH), which can be further catabolized to homocysteine by SAH-hydrolase ${ }^{(4)}$. Homocysteine is remethylated by a vitamin $\mathrm{B}_{12^{-}}$and folate-dependent pathway to methionine or metabolized via formation of cystathionine with serine to $\alpha$-ketobutyrate and cysteine or secreted into the plasma ${ }^{(5)}$.

Because methionine metabolism is the only known source for homocysteine in mammals, excessive methionine uptake might lead to the various pathophysiological consequences associated with hyperhomocysteinaemia ${ }^{(3)}$. Elevated plasma homocysteine concentration (hyperhomocysteinaemia) is regarded as an independent risk indicator for cardiovascular events ${ }^{(6)}$ and is associated with renal dysfunction ${ }^{(7)}$, neuronal diseases ${ }^{(8)}$ and complications in pregnancy ${ }^{(9,10)}$. Elevated plasma homocysteine may be caused by enzyme deficiencies ${ }^{(11,12)}$ or by malnutrition, e.g. vitamin depletion ${ }^{(8,13)}$ or a high methionine intake ${ }^{(6,14)}$.
Several theories have been put forward to explain the pathomechanisms associated with hyperhomocysteinaemia. Under in vitro conditions, homocysteine can interact with various enzymes, leading to an inhibition of the respective enzymatic reaction. This has been described for tyrosinase ${ }^{(11)}$, histidine ammonia-lyase $^{(15)}$ or dimethylargininase $(\mathrm{DDAH})^{(16)}$. Inhibition of DDAH may consequently lead to accumulation of asymmetrical dimethylarginine (ADMA), which is an inhibitor of endothelial nitric oxide synthase (eNOS). Elevated ADMA diminishes production of nitric oxide and contributes to endothelial dysfunction, making elevated plasma ADMA levels a risk factor for $\mathrm{CVD}^{(17)}$. Adenosine is another known regulator of vessel diameter ${ }^{(18)}$. Extracellular adenosine concentrations might be lowered in hyperhomocysteinaemia due to a reversed SAH-hydrolase reaction ${ }^{(19,20)}$. Because this bidirectional pathway favours intracellular production of SAH, if homocysteine concentrations are increased, this may result in net consumption of adenosine and hence lowered adenosine concentrations ${ }^{(21)}$. Under those conditions, increased homocysteine concentrations may be reflected by elevated SAH plasma levels ${ }^{(22,23)}$. Changes of tissue SAH concentrations are an index for disorders in transmethylation metabolism, which, on one hand, may result in hypermethylation (more SAH is

Abbreviations: ADMA, asymmetrical dimethylarginine; DDAH, dimethylargininase; eNOS, endothelial nitric oxide synthase; iNOS, inducible nitric oxide synthase; MET, methionine-enriched diet; SAH, $S$-adenosylhomocysteine SAM, $S$-adenosylmethionine; SDMA, symmetrical dimethylarginine.

* Corresponding author: A. Deussen, fax +493514586301, email andreas.deussen@tu-dresden.de 
formed) and, on the other hand, in hypomethylation (SAH inhibits various methyltransferases) ${ }^{(24,25)}$.

A previous study in human subjects has addressed shortterm effects $(1-7 \mathrm{~d})$ of methionine or methionine-enriched diet (MET) on homocysteine plasma levels ${ }^{(26)}$. It was found that plasma homocysteine was unaltered. The present study, conducted in rats, was designed to explore the impact of elevated methionine supplementation over a longer period of time and to assess metabolic consequences more comprehensively with regard to different organs, in addition to the commonly used plasma measurements. With regard to homocysteine-related diseases reported in literature we chose to analyse kidney ${ }^{(7)}$, heart ${ }^{(6)}$ and brain ${ }^{(8)}$. In addition, liver was analysed, because of its special importance for homocysteine metabolism, which includes a second remethylation pathway with betaine as methyl donor and a particularly high activity of the enzymes involved in homocysteine metabolism ${ }^{(3)}$. Measurements of spleen were included, because this organ is a major blood storage. Furthermore, the potential cardiovascular risk as mediated via homocysteine pathogenicity was addressed by measurement of plasma concentrations of adenosine and dimethylarginine (symmetric and asymmetric). Cholinergic mesenteric artery relaxation was quantified as a model of endothelium-dependent vessel function. An effect of homocysteine feeding on cholinergic aorta relaxation has been shown in literature ${ }^{(27)}$. We decided to use a methionine, not a homocysteine, feeding model, as the concentrations of homocysteine in food are far lower than those of methionine ${ }^{(28)}$. The methionine supplementation was chosen to reflect the upper range that may be consumed additionally during over-nutrition in human individuals.

\section{Methods}

\section{Animals and tissue preparation}

The experimental project was approved by the University Commission on Animal Experiments with regard to the animal welfare regulations of Germany, which conform to National Institutes of Health guidelines. A written permission for the study was issued by the German local authorities (24-9168-11-1-2004-16).

Male Wistar rats (Charles River Laboratories, Sulzfeld, Germany) were fed either a normal (control, $n$ 9) or MET ( $n$ 9) with $4 \mathrm{~g} / \mathrm{l}$ methionine (Sigma, Taufkirchen, Germany) in the drinking water ad libitum (approximately $40 \mathrm{ml} / \mathrm{d}$ ). The rationale for choosing this condition was to reflect a 3-4-fold increased methionine intake, as it might occur in human individuals due to over-nutrition. The regular pellet diet (Ssniff, Soest, Germany) contained $0.35 \mathrm{~g}$ methionine per $100 \mathrm{~g}$ and was given to both groups of rats ad libitum (approximately $20 \mathrm{~g} / \mathrm{d}$ ). A duration of 4 weeks feeding was chosen to induce steady state hyperhomocysteinaemia ${ }^{(29)}$.

After 4 weeks, animals were killed by $\mathrm{CO}_{2}$ exposure, blood was drawn from the vena cava in Li-heparin tubes (Sarstedt, Nuernbrecht, Germany) and plasma was separated from corpuscles immediately after collection by centrifugation at $2000 \mathrm{~g}$. Leucocytes were removed and erythrocytes were washed with $0.9 \% \mathrm{NaCl}$ solution and stored at $-80^{\circ} \mathrm{C}$ for analysis of homocysteine. Liver, heart, spleen, kidney and brain were immediately frozen in liquid $\mathrm{N}_{2}$ and stored at $-80^{\circ} \mathrm{C}$ for analysis of metabolites. Additionally, tissue samples of liver and lung were frozen at $-20^{\circ} \mathrm{C}$ for western blot analysis. For test of vascular function, the mesentery and attached tissue was removed and placed into ice-cold physiological saline solution containing $119 \mathrm{mmol} / \mathrm{l} \mathrm{NaCl}$, $4.7 \mathrm{mmol} / 1 \mathrm{KCl}, 1.17 \mathrm{mmol} / 1 \mathrm{MgSO}_{4}, 1.18 \mathrm{mmol} / 1 \mathrm{KH}_{2} \mathrm{PO}_{4}$, $25 \mathrm{mmol} / \mathrm{l} \quad \mathrm{NaHCO}_{3}, \quad 5.5 \mathrm{mmol} / \mathrm{l}$ glucose, $0.027 \mathrm{mmol} / \mathrm{l}$ EDTA and $2.5 \mathrm{mmol} / 1 \mathrm{CaCl}_{2}$.

\section{Isometric force measurement}

Vessel function was determined on a Mulvany myograph (Power Lab/400; AD-Instruments, Spechbach, Germany) connected to a PC by interface Model 410A (Danish Myo Technologies, Aarhus, Denmark) using mesenteric arterial vessels $^{(30)}$. The software Chart v4.1.2 (AD Instruments, Spechbach, Germany) was used for data acquisition. Freshly isolated mesenteric arteries were cleared from surrounding adipose tissue and cut into segments of about $2 \mathrm{~mm}$ width. The rings were carefully mounted in a computer-linked force transducer located in a $10 \mathrm{ml}$ organ chamber (Mitutoyo, Kawasaki, Japan) filled with physiological saline solution. The organ bath was warmed to $37^{\circ} \mathrm{C}$ and continuously bubbled with $5 \% \mathrm{CO}_{2}$ and $95 \% \mathrm{O}_{2}$ to maintain $\mathrm{pH}$ at 7.4. Rings were equilibrated with a resting tension equivalent to that obtained by exposure to an intraluminal pressure of $100 \mathrm{~mm} \mathrm{Hg}$. Maximum contraction was obtained by exposure of vessel rings to $\mathrm{K}$-enriched physiological saline solution, containing $123.7 \mathrm{mmol} / 1 \mathrm{KCl}, 1.17 \mathrm{mmol} / 1 \mathrm{MgSO}_{4}$, $1.18 \mathrm{mmol} / \mathrm{l} \quad \mathrm{KH}_{2} \mathrm{PO}_{4}, \quad 25 \mathrm{mmol} / \mathrm{l} \quad \mathrm{NaHCO}_{3}, \quad 5.5 \mathrm{mmol} / \mathrm{l}$ glucose, $0.027 \mathrm{mmol} / 1$ EDTA and $2.5 \mathrm{mmol} / 1 \mathrm{CaCl}_{2}$. Vasoconstriction was induced with $7.5 \mu \mathrm{mol} / 1$ noradrenalin. Endothelium-dependent vasorelaxation of mesenteric arteries was determined using acetylcholine (1 to $3 \mu \mathrm{mol} / \mathrm{l}$ ) and endothelium-independent relaxation using sodium-nitroprusside $(0 \cdot 3$ to $3 \mu \mathrm{mol} / \mathrm{l})$. $\mathrm{EC}_{50}$-values were calculated from these concentration-response curves.

Western blot analysis of endothelial nitric oxide synthase and inducible nitric oxide synthase

Proteins were isolated by chloroform/methanol precipitation and protein content was determined by amidoblack method as published ${ }^{(31)}$. Identical amounts of protein were used for each lane. For western blot analysis of eNOS from lung and liver, proteins were separated by $7.5 \%$ SDS-PAGE. For analysis of inducible nitric oxide synthase (iNOS), proteins were separated on a $5 \%$ SDS-polyacrylamide gel. Separated proteins were transferred to nitrocellulose membranes (Amersham, Munich, Germany) by electro blotting. Anti-eNOS and anti-iNOS were purchased from BD Pharmingen (Heidelberg, Germany) and anti- $\beta$-tubuline was purchased from Sigma (Taufkirchen, Germany). eNOS and iNOS were detected by ECL western blotting detection reagents (Amersham, Munich, Germany). Horseradish peroxidase-conjugated goat anti-rabbit IgG and sheep anti-mouse $\operatorname{IgG}$ were purchased from Dianova (Hamburg, Germany). Protein expression was calculated as intensity of blotting bands relative to $\beta$-tubuline. 
Liquid chromatography-tandem MS analysis of arginine, asymmetrical and symmetrical dimethylarginine

ADMA and symmetrical dimethylarginine (SDMA) were determined together with arginine by liquid chromatography-tandem MS as described previously ${ }^{(32)}$. In brief, samples $(50 \mu \mathrm{l})$ were precipitated with $100 \mu \mathrm{l}$ acetone and supernatants were derivatized with $100 \mu \mathrm{l} 1 \mathrm{M}-\mathrm{HCl}$ in butanol $\left(20 \mathrm{~min}, 65^{\circ} \mathrm{C}\right)$ after evaporation. Deuterated ADMA $(2 \mu \mathrm{mol} /$ $1 ; \mathrm{d}_{6}$-ADMA) and $50 \mu \mathrm{mol} / \mathrm{l}$ deuterated arginine $\left(\mathrm{d}_{7}\right.$-arginine $)$ were added as internal standards prior to precipitation. Butyl ester derivatives of arginine, ADMA and SDMA were analysed in the electron spray ionisation (ESI) positive mode. The daughter ions $\mathrm{m} / \mathrm{z} 70,214$ and 228 were scanned for arginine, ADMA and SDMA, respectively. The daughter ions with $\mathrm{m} / \mathrm{z}$ ratios of 77 and 220 were scanned for the internal standards $\mathrm{d}_{7}$-arginine and $\mathrm{d}_{6}$-ADMA, respectively. Peak area ratio was determined and concentrations $(\mu \mathrm{mol} / \mathrm{l})$ were calculated according to calibration curves.

\section{HPLC analysis of homocysteine}

Plasma total homocysteine levels were measured by HPLC with a ready-to-use kit (Immundiagnostic, Bensheim, Germany) after reduction of disulfide bounds. HPLC analysis was performed on a Waters Alliance liquid chromatography module (Waters, Eschborn, Germany) with a Merck-Hitachi fluorescence detector (Merck, Darmstadt, Germany) working at excitation/emission wavelengths of $\lambda_{\mathrm{ex}} 385 \mathrm{~nm}$ and $\lambda_{\mathrm{em}}$ $515 \mathrm{~nm}$. Separation was carried out on a Novapac RP-C18 column (Waters). Tissue and erythrocyte sample preparations were as follows. Tissue samples were homogenized with a half-automated Potter homogenizer in ice-cold $0.1 \mathrm{~mol} / \mathrm{l}$ perchloric acid (6 $\mathrm{ml}$ per $\mathrm{g}$ tissue). Samples were neutralized immediately after homogenization with $1 \mathrm{~mol} / 1 \mathrm{~K}_{3} \mathrm{PO}_{4}$. Erythrocytes $(500 \mu \mathrm{l})$ were disrupted with $300 \mu \mathrm{l} 0 \cdot 1 \mathrm{~mol} / \mathrm{l}$ perchloric acid and then immediately neutralized.

\section{HPLC analysis of plasma adenosine and} S-adenosylhomocysteine

HPLC analysis was based on $1, N^{6}$-etheno-derivatization of the adenine body. Derivatization and HPLC conditions were adapted from Haink \& Deussen ${ }^{(33)}$ with few modifications. In $200 \mu \mathrm{l}$ plasma samples, proteins were precipitated with $100 \mu \mathrm{l}$ perchloric acid $(1 \mathrm{~mol} / \mathrm{l})$ and separated by centrifugation for $15 \mathrm{~min}$ at $20000 \mathrm{~g}$ and $4^{\circ} \mathrm{C}$. Samples were neutralized with $\mathrm{K}_{3} \mathrm{PO}_{4}(1 \mathrm{~mol} / \mathrm{l})$ and precipitated potassium perchlorate was removed by centrifugation for $15 \mathrm{~min}$ at $20000 \mathrm{~g}$ and $4^{\circ} \mathrm{C}$. From the supernatant, $143 \mu \mathrm{l}$ were added to $51 \mu \mathrm{l}$ citrate-phosphate-buffer (containing $0.1 \mathrm{~mol} / \mathrm{l}$ citric acid and $\left.0.2 \mathrm{~mol} / 1 \mathrm{Na}_{2} \mathrm{HPO}_{4}, \mathrm{pH} 4\right)$. Derivatization was started by addition of $6 \mu \mathrm{l}$ chloracetaldehyde (40\%; Merck). HPLC analysis was performed on the Waters Alliance liquid chromatography module connected to a Merck Hitachi fluorescence detector $\left(\lambda_{\mathrm{ex}} 280 \mathrm{~nm}, \lambda_{\mathrm{em}} 410 \mathrm{~nm}\right)$. Separation was carried out on an XTerraMS-C18 column $(4.6 \times 50 \mathrm{~mm}$, particle size $5 \mu \mathrm{m}$; Waters) using a linear phosphate-buffer/acetonitrile gradient (from 6 to $24 \%$ acetonitrile over $5.6 \mathrm{~min}$ ) with ion-pair reagent tetrabutylammoniumsulfate $(5.7 \mathrm{mmol} / \mathrm{l})$ at
$\mathrm{pH} 5 \cdot 8$. Retention time was $1.0 \mathrm{~min}$ for $\mathrm{SAH}$ and $1.3 \mathrm{~min}$ for adenosine.

\section{HPLC analysis of $\mathrm{S}$-adenosylmethionine and $\mathrm{S}$-adenosylhomocysteine in tissues}

HPLC analysis was based on $1, N^{6}$-etheno-adenosine derivatives of SAM and SAH as described previously ${ }^{(34)}$ with few modifications. In brief, tissues were homogenized, acidified and neutralized as described earlier for tissue homocysteine analysis. Supernatant $(200 \mu \mathrm{l})$ was adjusted to $\mathrm{pH} 5$ with $50 \mu \mathrm{l}$ ammonium acetate buffer $(0.6 \mathrm{~mol} / \mathrm{l}, \mathrm{pH} 5)$. Derivatization procedure was started by addition of $50 \mu \mathrm{l}$ chloracetaldehyde ( $40 \%$; Merck). After $8 \mathrm{~h}$ at $39^{\circ} \mathrm{C}$, samples were frozen to $-20^{\circ} \mathrm{C}$ until day of analysis. HPLC analysis was performed on a Waters Alliance liquid chromatography module connected to a Merck Hitachi fluorescence detector $\left(\lambda_{\mathrm{ex}} 280 \mathrm{~nm}\right.$, $\left.\lambda_{\mathrm{em}} 410 \mathrm{~nm}\right)$. Separation was carried out on a RP-C18 column $(3.9 \times 150 \mathrm{~mm}$ Nova-Pak RP $18,4 \mu \mathrm{m}$; Waters $)$ applying a linear ammonium acetate/acetonitrile gradient (from 2 to $70 \%$ acetonitrile over $15 \mathrm{~min}$ ) with ion-pair reagent pentanesulfonic acid $(10 \mu \mathrm{mol} / \mathrm{l})$ at $\mathrm{pH}$ 5. Retention times were $4.8 \mathrm{~min}$ for $\mathrm{SAM}$ and $8.9 \mathrm{~min}$ for $\mathrm{SAH}$.

\section{GC-flame ionization detection analysis of methionine and other amino acids}

GC with flame ionization detection was performed to measure the plasma and tissue concentrations of amino acids. Tissues were homogenized in ice-cold $0.1 \mathrm{~mol} / \mathrm{l}$ perchloric acid. Precipitated proteins were removed by centrifugation for $15 \mathrm{~min}$ at $20000 \mathrm{~g}$ and $4^{\circ} \mathrm{C}$. Plasma was used for the test without protein precipitation. Sample preparation and analysis were performed with a ready-to-use kit (EZ:Faast; Phenomenex, Aschaffenburg, Germany). GC-flame ionization detection analysis was performed on a CP 3380 GC system (Varian, Darmstadt, Germany).

\section{Statistical analysis}

The experiment number necessary to detect intergroup differences was estimated by power analysis $(\alpha=0.05 ; \beta=0.8)$. Data are presented as mean values with their standard errors of the mean. Distribution of data was evaluated by KolmogorovSmirnov test. To assess differences of mean values between groups Student's $t$ test for unpaired data was used (two-sided). Correlation coefficient $r$ was calculated according to Pearson in the methionine feeding group. A value of $P<0.05$ was considered to indicate a statistically significant difference. Statistics were performed using SPSS for Windows (version 12.0; SPSS Inc.).

\section{Results}

Plasma concentrations of cardiovascular risk indicators

Rats consumed on average $20 \mathrm{~g}$ pellets per $\mathrm{d}$ and drank on average $40 \mathrm{ml}$ water. Calculated average methionine intake was $70 \mathrm{mg}$ per $\mathrm{d}$ in the control group and $230 \mathrm{mg}$ per $\mathrm{d}$ in the high methionine group, respectively (3-3-fold elevated intake). Plasma concentrations of risk indicators for disturbed 
cardiovascular functions are summarized in Table 1. Plasma homocysteine concentration was doubled $(P<0.05)$ in animals fed MET. Plasma concentrations of ADMA were not altered significantly by the MET. However, plasma concentrations of SDMA were significantly elevated in rats fed the MET. There was no significant change of arginine plasma level. Plasma concentrations of SAH and adenosine were not significantly altered by the MET.

\section{Effects on vessel function}

Examined vessel segments did not differ significantly between rats fed MET or a normal methionine diet with regard to length (control 1.7 (SEM 0.2) mm, MET 1.7 (SEM 0.2) mm) and internal diameter (control 316 (SEM 64) $\mu \mathrm{m}$, MET 308 (SEM 54) $\mu \mathrm{m}$ ). Acetylcholine and sodium nitroprusside, respectively, evoked the typical concentration-related vasorelaxations in the mesenteric vessel preparations. Half maximal relaxations were obtained at $7.19\left(\mathrm{SEM} \quad 0.78 \times 10^{-8}\right) \mathrm{mol} / \mathrm{l}$ for acetylcholine and $7.24 \times 10^{-5}\left(\right.$ SEM $\left.1.38 \times 10^{-5}\right) \mathrm{mol} / 1$ for sodium nitroprusside in vessels from control rats. In animals receiving MET, the endothelium dependent $\left(7.49 \times 10^{-8}\left(\mathrm{SEM} 1.66 \times 10^{-8}\right) \mathrm{mol} / \mathrm{l}\right)$ and independent $\left(4.43 \times 10^{-5}\left(\right.\right.$ SEM $\left.\left.0.90 \times 10^{-5}\right) \mathrm{mol} / \mathrm{l}\right)$ vasorelaxations were similar to those assessed in the control group. eNOS expression was similar in lung and liver extracts of rats fed a control diet (Fig. 1). iNOS expression was lower than eNOS expression as assessed in lung. There was no statistically significant difference in iNOS or eNOS expression in rats fed MET as compared with animals fed the control diet.

\section{Tissue concentration of homocysteine and its precursors}

Tissue levels of homocysteine largely differed among organs of control rats. Highest homocysteine tissue levels were found in liver $(34.2(\operatorname{SEM} 5.0) \mathrm{nmol} / \mathrm{g})$ and lowest levels were found in kidney (8.6 (SEM 1.3) nmol/g) (Fig. 2). MET had no significant effect on homocysteine levels of liver, heart, kidney and brain. However, the homocysteine level of spleen was significantly $(P<0.05)$ elevated in rats that had received MET. Homocysteine level of erythrocytes was unaltered in rats fed MET (1.4 (SEM 0.5) $\mu \mathrm{mol} / \mathrm{l})$ as compared with control animals (1.3 (SEM 0.5) $\mu \mathrm{mol} / \mathrm{l})$. To address relationships between plasma and spleen homocysteine, the respective

Table 1. Cardiovascular risk indicators in blood plasma†

(Values are means with their standard errors)

\begin{tabular}{lccccc}
\hline & \multicolumn{2}{c}{ Control } & & \multicolumn{2}{c}{ Methionine } \\
\cline { 2 - 3 } & Mean & SEM & & Mean & SEM \\
\hline Homocysteine $(\mu \mathrm{mol} / \mathrm{l})$ & 1.17 & 0.51 & & $2.35^{*}$ & 0.72 \\
ADMA $(\mu \mathrm{mol} / \mathrm{l})$ & 0.66 & 0.07 & & 0.78 & 0.04 \\
SDMA $(\mu \mathrm{mol} / \mathrm{l})$ & 0.15 & 0.02 & & $0.22^{*}$ & 0.01 \\
Arginine $(\mu \mathrm{mol} / \mathrm{l})$ & 138 & 15 & & 154 & 9 \\
SAH $(\mu \mathrm{mol} / \mathrm{l})$ & 0.94 & 0.20 & & 1.09 & 0.25 \\
Adenosine $(\mu \mathrm{mol} / \mathrm{l})$ & 0.69 & 0.09 & & 0.73 & 0.12 \\
Essential amino & 899 & 104 & & $1253^{*}$ & 123 \\
\multicolumn{1}{c}{ acids $(\mu \mathrm{mol} / \mathrm{l})$} & & & & \\
\hline
\end{tabular}

ADMA, asymmetrical dimethylarginine; SDMA, symmetrical dimethylarginine;

SAH, S-adenosylhomocysteine.

*Mean values were significantly different from control $(P<0.05)$

†For details of diets and procedures, see Methods. correlations were calculated using the data from individual experiments. Within the methionine group, homocysteine was elevated in plasma and spleen, but no significant correlation existed $(r-0 \cdot 177 ; P=0 \cdot 512)$. There was also no significant correlation between erythrocyte and spleen homocysteine levels $(r-0 \cdot 144 ; P=0.596)$.

While 4 weeks of MET was associated with enhanced homocysteine plasma levels (Table 1), no significant elevation of plasma methionine was found in animals fed MET (71 (SEM 14) $\mu \mathrm{mol} / \mathrm{l}$ ) compared with the control group (50 (SEM 6) $\mu \mathrm{mol} / \mathrm{l})$. Tissue concentrations of methionine, SAM, SAH and the ratio of both substances, often referred to as "transmethylation potential', are summarized in Table 2. From the various organs studied, only the spleen showed a significantly elevated methionine concentration after MET. Spleen also showed the highest methionine level among the studied organs, followed by kidney. Under control conditions, SAM level was highest in liver and approximately $50 \%$ lower in heart, spleen and kidney. Brain SAM level was only onethird of that in liver. MET did not significantly change SAM levels in any organ studied. Control SAH level was highest in liver followed by kidney ( $40 \%$ lower). Brain, heart and spleen showed SAH levels in the order of 10 to $20 \%$ of those found in liver. MET further enhanced liver SAH level, but did not change SAH levels of other organs studied. Despite the increase of liver SAH, the transmethylation potential was not significantly decreased in this organ. The sum of essential amino acids (valine, leucine, isoleucine, threonine, methionine, phenylalanine, lysine, tryptophan) was significantly elevated in plasma of rats fed MET (Table 1), but unchanged in organ tissues (data not shown).

\section{Discussion}

High methionine uptake has been discussed controversially as a potential risk for elevation of plasma homocysteine ${ }^{(2,6,14,35)}$. In human subjects, a single application of a high methionine dose $(0 \cdot 1 \mathrm{~g} / \mathrm{kg})$ resulted acutely in increased plasma homocysteine ${ }^{(14)}$. However, a diet containing twice the daily intake $(2 \cdot 1 \mathrm{~g} / \mathrm{d}$ instead of $1.1 \mathrm{~g} / \mathrm{d})$ in volunteers showed no significantly elevated plasma homocysteine after 1 week ${ }^{(26)}$. Because the rat model permits the assessment of organ metabolite levels in addition to plasma levels, this approach may provide interrelations of methionine and homocysteine metabolism and thus add important information to human studies. In the present study, 4 weeks of MET resulted in a 2-fold elevated homocysteine plasma level in male Wistar rats. Our experiments reflect conditions like those found in moderate hyperhomocysteinaemia, e.g. observed during malnutrition ${ }^{(6)}$. One important question to be addressed in the present study is whether the doubling of plasma homocysteine over 4 weeks of MET resulted in changes of endothelium-dependent mesenteric artery function as a standard model of arterial vessel relaxation ${ }^{(30)}$. We found no significant difference between the vessel function of mesenteric arteries of animals fed MET compared with controls. Other studies ${ }^{(36)}$ found significantly altered arteriolar function in rats in response to 4 weeks of MET. However, it should be noted, that these authors used far higher feeding doses of methionine $(1 \mathrm{~g} / \mathrm{kg}$ body weight per $\mathrm{d}$ ), which resulted in a higher increase in plasma homocysteine (from $7 \cdot 1$ to $23.6 \mu \mathrm{mol} / \mathrm{l}$ ), as compared 

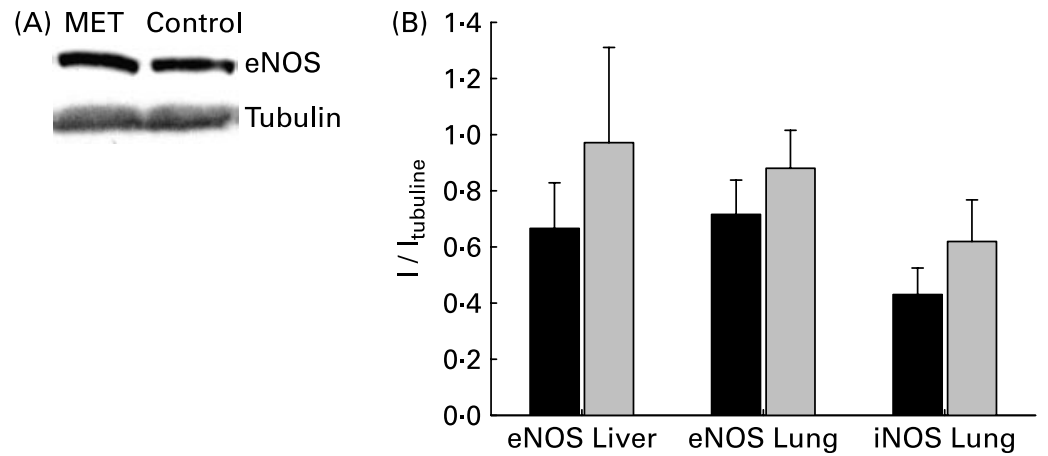

Fig. 1. Expression of inducible (iNOS) and endothelial nitric oxide synthase (eNOS). (A) Representative examples of western blotting bands of eNOS and tubuline from liver; (B) density of blotting bands relative to tubuline from liver and lung. $\mathbf{\square}$, Methionine-enriched diet (MET); $\square$, control diet (Control). Data are presented as means with their standard errors of the mean for nine animals per group. For details of diets and procedures, see Methods.

with the present study. The methionine dose applied in the present study was chosen to reflect the upper limit of human malnutrition (3-4-fold elevation of methionine uptake). Thus, pathophysiological effects reported in the earlier study $^{(36)}$ are unlikely to result from malnutrition.

We tested for an influence of the diet on eNOS expression in lung and liver and iNOS expression in lung, but did not find any altered expression. Homocysteine was described to stimulate the expression of iNOS in macrophages in vitro ${ }^{(37)}$. We were unable to prove this effect in vivo. We conclude from our study that 2-fold elevation of plasma homocysteine induced by MET (3.3-fold elevation of methionine uptake) has no impact on endothelium-dependent mesenteric artery relaxation and no pronounced effects on eNOS and iNOS expression.

As many of the proposed effector mechanisms of hyperhomocysteinaemia are based on direct interactions of homocysteine with enzymes inside cells, e.g. inhibition of DDAH by homocysteine leading to an elevated concentration of ADMA, we have tested whether the homocysteine content in erythrocytes, spleen, brain, liver, kidney and heart was altered after 4 weeks of MET. A significant elevation of tissue homocysteine was only found in spleen. Because

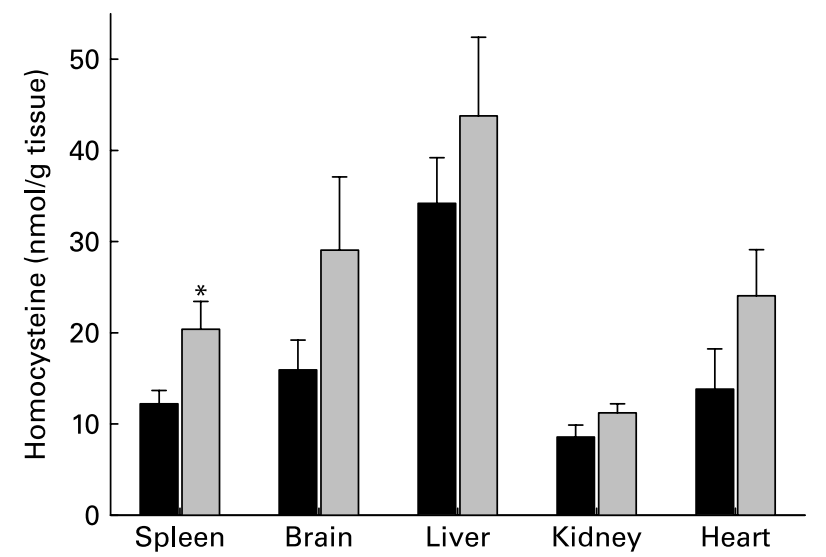

Fig. 2. Tissue concentrations of homocysteine in rats. $\mathbf{\square}$, Control diet; $\square$ methionine-enriched diet. Data are presented as means with their standard errors of the mean for nine animals per group. *Mean value was significantly different from control $(P<0.05)$. For details of diets and procedures, see Methods. spleen is a major blood storage, we considered whether homocysteine present in plasma, erythrocytes or leucocytes might have contributed to the augmented homocysteine concentration in this organ. However, correlations of homocysteine concentrations in plasma and spleen and in erythrocytes and spleen did not reveal a significant relationship. Thus, stored plasma or erythrocytes cannot explain elevated spleen homocysteine. Because homocysteine concentrations of leucocytes were not measured in the present study, leucocytes remain a possibility to explain the elevation of homocysteine levels in spleen. In this respect, it is noted here that cultured mononuclear blood cells have been described to exhibit an enhanced secretion of homocysteine under conditions of elevated methionine concentration ${ }^{(38)}$.

Disorders in transmethylation metabolism are another commonly described effector mechanism of hyperhomocysteinaemia. Although SAM and SAH may decrease shortly after administration of methionine ${ }^{(39)}$, in long-term experiments, as performed here, elevations of both metabolites are expected ${ }^{(34)}$. The increase of the transmethylation product SAH in liver after methionine feeding (Table 2) may be explained by the following two alternatives: first, by substrate saturation of SAHhydrolase ${ }^{(3)}$; second, by reversed action of this bidirectional enzyme, when homocysteine concentrations are raised ${ }^{(40)}$. Liver homocysteine concentrations were not significantly altered. Thus, an enhanced synthesis of SAH from adenosine and homocysteine is unlikely and the enhanced SAH level most likely indicates an accelerated methionine metabolism via transmethylation reactions and a rate-limitation of this pathway by activity of SAH-hydrolase.

Elevated homocysteine has been associated with elevated levels of ADMA, because homocysteine may inhibit DDAH, an ADMA catabolizing enzyme ${ }^{(16,17)}$. As shown in Table 1, the mean ADMA plasma concentration was higher in the methionine group as compared with control animals, but this difference did not reach statistical significance. Another link between homocysteine and arginine metabolism is the transmethylation of arginine to SDMA or $\mathrm{ADMA}^{(41)}$. As SDMA plasma concentrations were significantly elevated in the methionine enriched-fed animals compared with the control group, an enhanced methylation of arginine might explain the trend of ADMA elevation rather than inhibited ADMA degradation via DDAH. The fact that ADMA was not significantly changed in the current study is compatible 
Table 2. Methionine, S-adenosylmethionine (SAM), S-adenosylhomocysteine (SAH) and transmethylation potential (SAM/SAH) in various tissues under control conditions and 4 weeks of methionine-enriched diet $(\mathrm{nmol} / \mathrm{g}) \dagger$ (Values are means with their standard errors)

\begin{tabular}{|c|c|c|c|c|c|c|c|c|c|c|c|}
\hline & & \multicolumn{2}{|c|}{ Brain } & \multicolumn{2}{|c|}{ Heart } & \multicolumn{2}{|c|}{ Liver } & \multicolumn{2}{|c|}{ Spleen } & \multicolumn{2}{|c|}{ Kidney } \\
\hline & & Mean & SEM & Mean & SEM & Mean & SEM & Mean & SEM & Mean & SEM \\
\hline & Methionine & 60 & 14 & 58 & 10 & 58 & 6 & $195^{\star}$ & 24 & 125 & 17 \\
\hline \multirow[t]{2}{*}{ SAM } & Control & $30 \cdot 1$ & 1.5 & $56 \cdot 5$ & $5 \cdot 2$ & $103 \cdot 2$ & 5.9 & $60 \cdot 1$ & $5 \cdot 4$ & $63 \cdot 3$ & 1.9 \\
\hline & Methionine & $30 \cdot 4$ & $1 \cdot 7$ & $60 \cdot 3$ & $6 \cdot 4$ & $123 \cdot 7$ & $8 \cdot 8$ & $63 \cdot 2$ & $4 \cdot 3$ & $65 \cdot 4$ & $1 \cdot 8$ \\
\hline \multirow[t]{2}{*}{ SAM/SAH } & Control & $13 \cdot 7$ & $2 \cdot 2$ & $6 \cdot 4$ & 0.8 & $3 \cdot 4$ & 0.3 & $3 \cdot 7$ & 0.2 & $18 \cdot 5$ & $2 \cdot 5$ \\
\hline & Methionine & $17 \cdot 0$ & $2 \cdot 4$ & $7 \cdot 1$ & 0.9 & $3 \cdot 2$ & 0.4 & $3 \cdot 3$ & 0.2 & $17 \cdot 8$ & 1.8 \\
\hline
\end{tabular}

${ }^{*}$ Mean value was significantly different from control $(P<0.05)$.

$\dagger$ For details of diets and procedures, see Methods.

with the finding that acetylcholine-induced relaxation of mesenteric arteries was also unchanged after 4 weeks of an enriched methionine diet, which caused plasma homocysteine levels to double.

\section{Study limitations}

Methionine supply in the present study was scaled to reflect conditions of maximal dietary intake of human individuals. However, results obtained in experimental models should be treated with caution. When methionine is supplied in drinking water, the food uptake could be lowered, which might lead to a shortage of essential amino acids ${ }^{(42,43)}$. This effect might have influenced the results of the study, as a high methionine diet is typically not induced by enhanced uptake of the pure substance methionine but by over-nutrition, comprising a mix of various amino acids. Because we did not find an alteration of total amino acid content of plasma and of examined tissues, it is unlikely that MET disturbed food uptake in our study.

The present study was conducted in the rat, which has served as a model for studying homocysteine metabolism before ${ }^{(42-45)}$. As shown in Table 1, plasma homocysteine level in the rat is considerably lower than that in man (6 to $12 \mu \mathrm{mol} / \mathrm{l}$ ). Therefore, absolute levels should not be compared.

Taken together, we have found a significant, 2-fold elevation of plasma homocysteine following 4 weeks of MET. However, no alterations in the mesenteric artery vessel dilator function were observed. Furthermore, no alterations of risk indicators such as elevated plasma ADMA concentration, elevated plasma SAH or lowered plasma adenosine concentration were evident. We conclude that a 2-fold elevation of plasma homocysteine induced by 4 weeks of MET had only a small impact on tissue metabolites related to methionine and no significant impact on mesenteric artery dilatory function.

\section{Acknowledgements}

We thank Mariola Kastner, Sandra Tuchscheerer, Bianca Mueller and Birgit Zatschler for their technical assistance.

\section{References}

1. Young VR, Wagner DA, Burini R \& Storch KJ (1991) Methionine kinetics and balance at the $1985 \mathrm{FAO} / \mathrm{WHO} / \mathrm{UNU}$ intake requirement in adult men studied with L-[2H3-methyl-113C]methionine as a tracer. Am J Clin Nutr 54, 377-385.

2. Fonseca V, Guba SC \& Fink LM (1999) Hyperhomocysteinemia and the endocrine system: implications for atherosclerosis and thrombosis. Endocr Rev 20, 738-759.

3. Finkelstein JD (1998) The metabolism of homocysteine: pathways and regulation. Eur J Pediatr 157, Suppl. 2, S40-S44.

4. Kloor D, Stumvoll W, Schmid H, Kompf J, Mack A \& Osswald H (2000) Localization of S-adenosylhomocysteine hydrolase in the rat kidney. J Histochem Cytochem 48, 211-218.

5. Refsum H, Guttormsen $A B$, Fiskerstrand $T$ \& Ueland $P M$ (1998) Hyperhomocysteinemia in terms of steady-state kinetics. Eur J Pediatr 157, Suppl. 2, S45-S49.

6. De Bree A, Verschuren WM, Kromhout D, Kluijtmans LA \& Blom HJ (2002) Homocysteine determinants and the evidence to what extent homocysteine determines the risk of coronary heart disease. Pharmacol Rev 54, 599-618.

7. van Guldener C, Stam F \& Stehouwer CD (2005) Hyperhomocysteinaemia in chronic kidney disease: focus on transmethylation. Clin Chem Lab Med 43, 1026-1031.

8. Allen RH, Stabler SP \& Lindenbaum J (1998) Relevance of vitamins, homocysteine and other metabolites in neuropsychiatric disorders. Eur J Pediatr 157, Suppl. 2, S122-S126.

9. El Khairy L, Vollset SE, Refsum H \& Ueland PM (2003) Plasma total cysteine, pregnancy complications, and adverse pregnancy outcomes: the Hordaland Homocysteine Study. Am J Clin Nutr 77, 467-472.

10. Ingec M, Borekci B \& Kadanali S (2005) Elevated plasma homocysteine concentrations in severe preeclampsia and eclampsia. Tohoku J Exp Med 206, 225-231.

11. Reish O, Townsend D, Berry SA, Tsai MY \& King RA (1995) Tyrosinase inhibition due to interaction of homocyst(e)ine with copper: the mechanism for reversible hypopigmentation in homocystinuria due to cystathionine beta-synthase deficiency. Am J Hum Genet 57, 127-132.

12. Blom HJ (1998) Mutated 5,10-methylenetetrahydrofolate reductase and moderate hyperhomocysteinaemia. Eur J Pediatr 157, Suppl. 2, S131-S134.

13. Herrmann W \& Obeid R (2005) Hyperhomocysteinemia and response of methionine cycle intermediates to vitamin treatment in renal patients. Clin Chem Lab Med 43, 1039-1047.

14. Bellamy MF, McDowell IF, Ramsey MW, Brownlee M, Bones C, Newcombe RG \& Lewis MJ (1998) Hyperhomocysteinemia after 
an oral methionine load acutely impairs endothelial function in healthy adults. Circulation 98, 1848-1852.

15. Klee CB (1974) Stereospecific irreversible inhibition of histidine ammonia-lyase by L-cysteine. Biochemistry 13, 4501-4507.

16. Stühlinger MC, Oka RK, Graf EE, et al. (2003) Endothelial dysfunction induced by hyperhomocyst(e)inemia: role of asymmetric dimethylarginine. Circulation 108, 933-938.

17. Böger RH, Lentz SR, Bode-Böger SM, Knapp HR \& Haynes WG (2001) Elevation of asymmetrical dimethylarginine may mediate endothelial dysfunction during experimental hyperhomocyst(e)inaemia in humans. Clin Sci (Lond) 100, 161-167.

18. Deussen A (2003) Adenosine - the missing link to understanding homocysteine pathogenicity or more smoke on the horizon? Cardiovasc Res 59, 259-261.

19. Chen YF, Li PL \& Zou AP (2002) Effect of hyperhomocysteinemia on plasma or tissue adenosine levels and renal function. Circulation 106, 1275-1281.

20. Riksen NP, Rongen GA, Blom HJ, Russel FG, Boers GH \& Smits P (2003) Potential role for adenosine in the pathogenesis of the vascular complications of hyperhomocysteinemia. Cardiovasc Res 59, 271-276.

21. Borst MM, Deussen A \& Schrader J (1992) S-adenosylhomocysteine hydrolase activity in human myocardium. Cardiovasc Res 26, 143-147.

22. Kerins DM, Koury MJ, Capdevila A, Rana S \& Wagner C (2001) Plasma S-adenosylhomocysteine is a more sensitive indicator of cardiovascular disease than plasma homocysteine. Am J Clin Nutr 74, 723-729.

23. Yi P, Melnyk S, Pogribna M, Pogribny IP, Hine RJ \& James SJ (2000) Increase in plasma homocysteine associated with parallel increases in plasma S-adenosylhomocysteine and lymphocyte DNA hypomethylation. J Biol Chem 275, 29318-29323.

24. Perna AF, Capasso R, Lombardi C, Acanfora F, Satta E \& Ingrosso D (2005) Hyperhomocysteinemia and macromolecule modifications in uremic patients. Clin Chem Lab Med 43, 1032-1038.

25. Ingrosso D, Cimmino A, Perna AF, et al. (2003) Folate treatment and unbalanced methylation and changes of allelic expression induced by hyperhomocysteinaemia in patients with uraemia. Lancet 361, 1693-1699.

26. Ward M, McNulty H, Pentieva K, McPartlin J, Strain JJ, Weir DG \& Scott JM (2000) Fluctuations in dietary methionine intake do not alter plasma homocysteine concentration in healthy men. $J$ Nutr 130, 2653-2657.

27. Dimitrova KR, DeGroot KW, Pacquing AM, Suyderhoud JP, Pirovic EA, Munro TJ, Wieneke JA, Myers AK \& Kim YD (2002) Estradiol prevents homocysteine-induced endothelial injury in male rats. Cardiovasc Res 53, 589-596.

28. Pexa A, Fischer K, Deussen A \& Henle T (2007) Homocysteine in food. Eur Food Res Tech Published online (14 February 2007, DOI 10.1007/s00217-007-0583-2).

29. Morita H, Kurihara H, Yoshida S, Saito Y, Shindo T, OhHashi Y, Kurihara Y, Yazaki Y \& Nagai R (2001) Dietinduced hyperhomocysteinemia exacerbates neointima formation in rat carotid arteries after balloon injury. Circulation 103, 133-139.
30. Buus NH, VanBavel E \& Mulvany MJ (1994) Differences in sensitivity of rat mesenteric small arteries to agonists when studied as ring preparations or as cannulated preparations. $\mathrm{Br} J$ Pharmacol 112, 579-587.

31. Dieckmann-Schuppert A \& Schnittler HJ (1997) A simple assay for quantification of protein in tissue sections, cell cultures, and cell homogenates, and of protein immobilized on solid surfaces. Cell Tissue Res 288, 119-126.

32. Schwedhelm E, Tan-Andresen J, Maas R, Riederer U, Schulze F \& Boger RH (2005) Liquid chromatography-tandem mass spectrometry method for the analysis of asymmetric dimethylarginine in human plasma. Clin Chem 51, 1268-1271.

33. Haink G \& Deussen A (2003) Liquid chromatography method for the analysis of adenosine compounds. $J$ Chromatogr $B$ Analyt Technol Biomed Life Sci 784, 189-193.

34. Loehrer FM, Tschopl M, Angst CP, Litynski P, Jager K, Fowler B \& Haefeli WE (2001) Disturbed ratio of erythrocyte and plasma Sadenosylmethionine/S-adenosylhomocysteine in peripheral arterial occlusive disease. Atherosclerosis 154, 147-154.

35. Lentz SR (1997) Homocysteine and vascular dysfunction. Life Sci 61, 1205-1215.

36. Ungvari Z, Pacher P, Rischak K, Szollar L \& Koller A (1999) Dysfunction of nitric oxide mediation in isolated rat arterioles with methionine diet-induced hyperhomocysteinemia. Arterioscler Thromb Vasc Biol 19, 1899-1904.

37. Woo CW, Cheung F, Chan VW \& Siow YLOK (2003) Homocysteine stimulates inducible nitric oxide synthase expression in macrophages: antagonizing effect of ginkgolides and bilobalide. Mol Cell Biochem 243, 37-47.

38. Schroecksnadel K, Frick B, Wirleitner B, Schennach H \& Fuchs D (2003) Homocysteine accumulates in supernatants of stimulated human peripheral blood mononuclear cells. Clin Exp Immunol 134, 53-56.

39. Young SN \& Shalchi M (2005) The effect of methionine and S-adenosylmethionine on S-adenosylmethionine levels in the rat brain. J Psychiatry Neurosci 30, 44-48.

40. Deussen A, Borst M \& Schrader J (1988) Formation of S-adenosylhomocysteine in the heart. I: An index of free intracellular adenosine. Circ Res 63, 240-249.

41. Böger RH, Bode-Böger SM, Sydow K, Heistad DD \& Lentz SR (2000) Plasma concentration of asymmetric dimethylarginine, an endogenous inhibitor of nitric oxide synthase, is elevated in monkeys with hyperhomocyst(e)inemia or hypercholesterolemia. Arterioscler Thromb Vasc Biol 20, 1557-1564.

42. Sugiyama K, Kushima Y \& Muramatsu K (1987) Effect of dietary glycine on methionine metabolism in rats fed a high-methionine diet. J Nutr Sci Vitaminol (Tokyo) 33, 195-205.

43. Rowling MJ, McMullen MH, Chipman DC \& Schalinske KL (2002) Hepatic glycine N-methyltransferase is up-regulated by excess dietary methionine in rats. $J$ Nutr 132, 2545-2550.

44. Kloor D, Stumvoll W, Schmid H, Kompf J, Mack A \& Osswald H (2000) Localization of S-adenosylhomocysteine hydrolase in the rat kidney. J Histochem Cytochem 48, 211-218.

45. Fell D \& Steele RD (1983) Effect of methionine on in vivo histidine metabolism in rats. $J$ Nutr $\mathbf{1 1 3}, 860-866$. 